\title{
FICÇÃO E REALIDADE OU LITERATURA E SOCIEDADE: LIMIARES
}

\section{Tiago Hermano Breunig ${ }^{*}$}

\begin{abstract}
Resumo: O presente trabalho pretende aprofundar o significado da afirmação de Peter Sloterdijk segundo a qual o humanismo naufraga como escola de formação humana por meio da literatura, postulando, por conseguinte, o fim da utopia da formação humana por meio da literatura, a qual supostamente promoveria uma resignação a partir da leitura e da escrita. Para tanto, interessa o fato de que o conceito de literatura proposto por Sloterdijk como uma comunidade subjacente ao humanismo se coaduna com o conceito de literatura proposto no Brasil por Antonio Candido, sobretudo na medida em que Sloterdijk sugere pensar o humanismo segundo o modelo de uma sociedade que recorda as academias mencionadas por Candido como formadoras da literatura brasileira, e a literatura como meio comunicativo pelos quais os homens se formam a si mesmos.
\end{abstract}

Palavras-chave: Literatura. Humanismo. Sociedade.

O barco misterioso

Ontem à noite, quando tudo dormia

E o vento, com lamentos

Indecisos, pelas vielas corria,

Não me dava repouso o travesseiro

Nem a papoula, nem o que normalmente

Dá sono profundo - a consciência tranqüila.

Enfim renunciei ao sono

E corri para a praia. Havia luar

E o tempo era bom - encontrei

O homem e o barco na areia morna,

Os dois sonolentos, pastor e ovelha: -

Sonolento, afastou-se da terra o barco.

Após uma hora, talvez duas,

Ou teria sido um ano? - subitamente

Meus sentidos e pensamentos mergulharam

Numa eterna monotonia,

E um abismo sem limites

Se abriu: - tudo acabou!

- Veio a manhã: em negras profundezas

Há um barco que repousa, repousa... * Doutor pelo Programa de Pós-Graduação em Literatura da Universidade Federal de Santa Catarina.
Professor colaborador da Universidade Estadual de Ponta Grossa. 
Que aconteceu? alguém gritou, logo gritaram

Centenas de vozes: que houve? Sangue? -

Nada aconteceu! Nós todos dormíamos,

Dormíamos - ah, tão bem!

Nietzsche, A gaia ciência

Reconhecer que a domesticação do ser humano é o grande impensado, do qual o humanismo desde a Antiguidade até o presente desviou os olhos, é o bastante para afundarmos em águas profundas.

Sloterdijk, Regras para o parque humano

Quando Pope afirma ser o Homem "o estudo adequado da humanidade" em seus versos, e os leitores tradicionais castigam o poema por se concentrar no "'homem' em vez de no 'homem imortal'" (NEIMAN, 2003, p. 49), o poeta, ao mesmo tempo que se coloca nos limiares da filosofia e da poesia, problematiza um humanismo que ainda cultivaria a literatura como campo privilegiado. Um humanismo livresco que se caracteriza, como sugere Peter Sloterdijk (1999, p. 58), por uma literatura que trata da formação humana, e que se situa, para tanto, nos limiares da ficção e da realidade.

Ao constatar que o humanismo naufraga, sobretudo como escola da formação humana por meio da literatura, Sloterdijk (2000, p. 60) tematiza "o perigoso fim" de um humanismo fundamentado na literatura como utopia da formação humana mediante a escrita e a leitura, as quais promoveriam "a atitude paciente" e educariam "para se julgar com circunspecção e manter os ouvidos abertos." Como a referida utopia se norteia por uma razão preocupada com a verdade, com a realidade ou o seu correlato para o historiador tradicional, a sociedade, em que as historiografias da literatura se firmam, a mimesis ou a representação teriam um papel fundamental, e o realismo seria privilegiado, apesar de a literatura questionar incessantemente a polaridade entre a ficção e a realidade.

Ao afirmar que a mimesis constitui "o termo mais geral e corrente sob o qual se conceberam as relações entre a literatura e a realidade", Antoine Compagnon (2001, p. 97) situa Erich Auerbach no centro das referidas relações, uma vez que sua "monumental obra" tematiza a representação da realidade na literatura ocidental. Auerbach (2009, p. 499) se limita a escrever, quanto ao conceito de mimesis que nomeia sua obra, que parte originalmente da interrogação de Platão da interpretação da realidade pela representação, colocada em terceiro lugar depois da verdade.

Com efeito, preocupado com a administração e a educação humana, Platão (2001, p. 449) entende que a fundação da cidade, principalmente "desde que definimos em separado cada uma das partes da alma", implica a "necessidade de recusar em absoluto" a poesia. E ao considerar a imitação uma produtividade de objetos distintos do que seria a "verdadeira realidade", reduzindo a representação a uma "imitação da imitação", afirma que a arte de imitar, ao mesmo tempo que "executa as suas obras longe da verdade", convive com a parte irracional da alma humana, de modo que a cidade deve excluir o poeta imitador.

Auerbach, no entanto, ao se propor a tratar da representação da realidade na literatura ocidental, questiona a concepção de mimesis proposta por Platão, que, afinal, a considera prejudicial e perigosa ao discurso ideal da filosofia. Em conformidade com o 
aristotelismo que refuta o conceito de mimesis de Platão, Auerbach parece enaltecer o valor da arte justamente pela autonomia da representação diante da verdade preestabelecida. Com o aristotelismo, a mimese se caracteriza "como a representação do que "poderia ser", o que garante a "autonomia da arte" (COSTA, 1992, p. 6), bem como pela congenialidade da imitação no homem. Assim, a imitação se manifesta naturalmente no homem como um meio que permite ao homem se elevar do particular para o universal e que o "difere dos outros viventes" (ARISTÓTELES, 1966, p. 203).

Ao tender para o universal, o que poderia acontecer, a poesia se configura como um meio para a educação humanista, pois aponta para o devir humano. Afinal, a universalidade da poesia consiste em atribuir ao homem de determinada natureza "pensamentos e ações" convenientes a tal natureza (ARISTÓTELES, 1966, p. 209). Assim, o aristotelismo redimensiona o significado da arte e, sobretudo, do homem, diferenciado do animal, os "outros viventes", justamente pela congenialidade da imitação. Mas ao representar a natureza, a arte, por conta da congenialidade da imitação, deve implicar, em vez da naturalização do humano, como percebe Hegel, a humanização da natureza. Ao afirmar que a arte consiste, em detrimento de uma "imitação da natureza", antes o oposto, em ensinar ao homem a ser humano, Hegel parece ter compreendido a profundidade de tal proposição, que inscreve o devir humano na universalidade da representação.

Assim, o papel civilizador da filosofia se estende para a literatura, que integra a tradição humanista que culmina nos "humanismos livrescos" de que trata Sloterdijk, com a noção de que a formação humana por meio da escrita e da leitura promove "o desembrutecimento do ser humano" ou a sua domesticação (SLOTERDIJK, 2000, p. 17). Tradição em que se inscreve Auerbach, movido por uma necessidade de aproximar a representação e a realidade pretensa a conjugar a totalidade da literatura ocidental. A proposta de Auerbach se define pela articulação de um panorama da representação da realidade na literatura ocidental, privilegiando, para tanto, fundamentalmente o realismo, de modo que a ordem social figura como uma realidade a ser interpretada por meio da representação da literatura ocidental, que culmina no realismo moderno, compreendido por Auerbach como correspondente da realidade concreta. ${ }^{1} \mathrm{O}$ tema central da obra de Auerbach, portanto, tanto fundamenta as teorias a respeito das relações entre literatura e sociedade que, no Brasil, refletem em Antonio Candido, por exemplo, quanto sustenta o problema fundamental que assombra o limiar entre a ficção e a realidade, a literatura e a sociedade.

Candido estabelece relações entre as obras e seu condicionamento social, sendo que a integridade da obra requer preservar associados os referidos elementos: fundem-se, assim, texto e contexto numa relação dialeticamente integral, de modo que externo e interno se integram na estrutura da obra. Para a literatura, portanto, o elemento social importa, segundo Candido (1976, p. 7), na medida em que "o externo se torna interno". E o autor revela como modelo Auerbach, que, conforme Candido, investiga os fatos da

\footnotetext{
${ }^{1}$ Erich Auerbach (2015, p. 369-370) antecipa sua inclinação ao realismo ao definir o mesmo como "a forma mais importante e a mais eficaz da literatura moderna", capaz de abranger "cada vez mais a totalidade da vida dos homens sobre a Terra".
} 
literatura sintetizando a dicotomia tradicional entre fatores externos e internos, em nome, no entanto, de uma "autonomia da obra" que se traduz em sua organicidade.

O problema reside exatamente nas fronteiras entre a realidade e a ficção: em que medida a literatura ocidental se fundamenta na realidade e em que medida a funda? Se a literatura constitui um aspecto da civilização, como postula Candido (1993), resta perguntar o que significa a civilização e, sobretudo, a que se opõe, bem como as concepções geralmente fundamentadas em polaridades dialeticamente organizadas, como a realidade e a ficção. Questionar os limiares da ficção e da realidade corresponde a questionar as polaridades suspensas da vida e da morte, da natureza e da cultura, do humano e do animal, da exclusão e da inclusão e do interno e do externo.

Em sua obra mais fundamental ou fundacional, em que projeta uma formação da literatura brasileira, Candido (1993, p. 9) "procura definir o valor e a função das obras", e, por meio das obras, "formar nossa sensibilidade e visão do mundo". Aparentemente convicto quanto ao significado de "literatura", Candido (1993, p. 23), em uma obra em que pretende sintetizar aspectos "universalistas e particularistas", parece ignorar o quanto pode ser exclusivo um conceito definitivo para "literatura", 2 que implica, inclusive, o humano. ${ }^{3}$

Segundo Candido (1993, p. 24), a literatura se configura quando, integrados e dinamizados, os fatores constitutivos do sistema se pluralizam, formando uma "tradição", que identifica a literatura com a "civilização". A noção de formação da literatura brasileira proposta por Candido, a partir de uma perspectiva historicista e hegeliana, ${ }^{4}$ implica uma continuidade conduzida por uma tradição, que se consolida, para Candido, a partir de meados do XVIII. Os fundadores da literatura brasileira seriam, assim, os poetas do arcadismo mineiro, tendo, no entanto, como predecessores as Academias dos

\footnotetext{
${ }^{2}$ Tanto que Antonio Candido exclui a literatura barroca. Haroldo de Campos (1989) entende que "se há um problema instante e insistente na historiografia literária brasileira, este problema é a 'questão da origem'." Haroldo critica a "perspectiva histórica" adotada por Antonio Candido (1993, p. 24) em Formação da Literatura Brasileira, em que afirma, com efeito, a respeito de Gregório de Matos, que "ele não existiu literariamente (em perspectiva histórica)". "De fato, essa 'perspectiva histórica' foi enunciada a partir de uma visão substancialista da evolução literária, que responde a um ideal metafísico de entificação do nacional" que, segundo Haroldo, atravessa a obra de Candido. "A Formação", observa Haroldo, "privilegia um tipo de história: a evolutivo-linear-integrativa, empenhada em demarcar, de modo encadeado e coerente, o roteiro de 'encarnação literária do espírito nacional', um certo tipo de tradição, ou melhor, 'uma certa continuidade da tradição'." “A 'perspectiva histórica é, pois”, conclui Haroldo "uma perspectiva ideológica."

3 Antonio Candido (1993, p. 23) define a literatura como uma "comunicação inter-humana".

${ }^{4}$ Inclusive, ao avaliar o desenvolvimento promovido pelas Academias Literárias na construção de uma tradição, Antonio Candido (1976, p. 173) escreve que "a concepção de história não se separava do registro de feitos individuais (...) A existência de uma nobreza, decorrente do serviço das armas, da governança, da produção econômica, provaria a existência de uma história (concebida como registro de feitos); portanto, de uma dignidade através do tempo." Ademais, além de demonstrar a mesma "preferência pelo número três" de que trata Sloterdijk (1999, p. 17) no que concerne "à reconstrução lógica hegeliana da história do mundo e do espírito", que reflete nos seus "modelos triádicos", como diria Haroldo de Campos, Candido, ao conceber a literatura como sistema, permanece preso a um pensamento tipicamente hegeliano. Afinal, para Hegel, "é somente como sistema que o saber é efetivamente real, e é somente assim que ele pode ser representado" (GARAUDY, 1983). Assim, o sistema faz parte da tentativa hegeliana de sintetizar o universal e o individual, que, a propósito, perdura em Candido, e aponta para a totalidade que culmina com a "formação do espírito universal" ou a "história da cultura universal".
} 
Seletos e a dos Renascidos, em que se verifica uma concepção da "literatura do Brasil como expressão da realidade local e, ao mesmo tempo, elemento positivo na construção nacional" (CANDIDO, 1993, p. 25).

Para Candido (1993, p. 17), essas sociedades possibilitaram uma comunidade comunicativa fornecendo os elementos para constituir a sua literatura em conformidade com a cultura ocidental: "o Arcadismo foi importante porque plantou de vez a literatura do Ocidente no Brasil, graças aos padrões universais por que se regia, e que permitiram articular a nossa atividade literária com o sistema expressivo da civilização a que pertencemos".

A concepção de literatura de Candido (1993, p. 48) implica uma comunicação e, por conseguinte, uma comunidade, mas em um sentido demasiado restrito e restritivo. $\mathrm{O}$ arcadismo se configura, segundo Candido (1993, p. 50), como uma literatura comunicativa e integrativa, na medida em que promove um ajustamento a uma ordem natural e social, conforme os ditames do humanismo inscrito em uma tradição europeia. Com a sua contribuição a um processo de "elaboração nacional", os arcadistas propagam "uma poesia civilizada", caracterizada por sua inteligibilidade "aos homens de cultura" (CANDIDO, 1993, p. 17). Ora, ao definir o humanismo como uma comunicação propiciadora de amizade por meio da escrita, em que escritores e leitores, compreendidos respectivamente como remetentes e receptores de mensagens constitutivas de escritos fundadores da comunidade, Sloterdijk (2000, p. 10) sugere pensar o humanismo segundo o modelo de uma sociedade que recorda as academias mencionadas por Candido como formadoras da literatura brasileira. E a literatura, como meio comunicativo pelos quais os homens se formam a si mesmos. O conceito de literatura empregado por Candido se coaduna, portanto, com o proposto por Sloterdijk (2000, p. 12), ou seja, o de uma comunidade subjacente ao humanismo, o qual reivindica "o valor universal das leituras nacionais" e "o valor nacional das leituras universais".

Mas o humanismo se esgotou completamente, conclui Sloterdijk (2000, p. 14), ao constatar que a sociedade moderna abandonou o modelo da sociedade fundada na "arte de escrever inspiradoras cartas de amor a uma nação de amigos", incapaz de representar a estrutura social. Ainda que o modelo humanista retorne tardiamente confiante no "poder civilizador e humanizador" da literatura, compreendida como meio comunicativo do humanismo, procurando redimir o passado recente "por meio de uma bibliofilia radicalizada", a exemplo de Auerbach e, no Brasil, de Candido, cuja acepção de literatura ocidental como "sistema expressivo da civilização a que pertencemos", permite entrever o problema do pertencimento, que subjaz ao conceito mesmo de humanidade, o qual, segundo Sloterdijk (1999, p. 14), oculta o paradoxo do se pertencer com os quais não se pertence. O humanismo representa, assim, a "ideologia oficial das grandes civilizações" (SLOTERDIJK, 1999, p. 18), a qual identifica o homem a partir da "grande civilização, a verdadeira humanidade", de modo que o homem aparece apenas a partir do modelo europeu para a cidade, o Estado ou a nação.

Antes, no entanto, que, com as Grandes Guerras e a consolidação da cultura de massas, o barco que navega entre as margens da ficção e da realidade naufragasse com o humanismo, o modelo das sociedades fundadas na literatura se ampliou para a norma da sociedade, observa Sloterdijk (2000, p. 11-12). A constatação de Sloterdijk parece ser 
prenunciada pelo ideal do homem natural do XVIII, como transparece Candido ao sugerir o triunfo do projeto humanista sobre a natureza humana. Candido (1993, p. 56-57) descreve o movimento de "assimilação do social ao natural", concebido como produto da "urbanização do homem", idealizado por uma literatura que repousa na "identidade do racional e do natural". Para tanto, e em conformidade com uma educação que se explicita, segundo Sloterdijk (2000, p. 38), como "teoria do adestramento aristocrata na cidade", as pastorais representam uma das "principais manifestações de naturalidade" em um "quadro natural interpretado segundo normas racionais" (CANDIDO, 1993, p. 57).

Não espanta que a literatura que Candido (1993, p. 67) considera como origem da literatura brasileira, a arcadista, seja guiada por uma "moda pastoril", recorrentemente ilustrada por imagens de pastores e ovelhas, signos dos ideais do homem natural, nobre e terno, de modo que, como constata Candido (1993, p. 56-57), "a literatura se desenvolve em grande parte, como trabalho de construção deste ideal". Um bom exemplo pode ser observado no seguinte fragmento de um poema arcadista -

\author{
Se em campos não pisados algum dia \\ Entra a Ninfa e o Pastor, a ovelha, o touro, \\ Efeitos são da vossa melodia; \\ Que muito, ó Musa, pois, que em fausto agouro, \\ Cresçam do pátrio rio à margem fria \\ A imarcescível hera, o verde louro!
}

- cujos versos, segundo Candido (1993, p. 102), representam o desejo de "fundar uma literatura que significasse a incorporação do Brasil à cultura do Ocidente, aclimatando nele, de vez para sempre, as disciplinas mentais que lhe pudessem exprimir a realidade." E o poeta mesmo parece reconhecer, de fato, a função civilizadora ou domesticadora da poesia e da literatura, sobretudo de integração cultural ao ocidente e de elaboração nacional, que se traduz pelo progresso e pela incorporação dos padrões europeus: "a moda pastoril encaminhou para a valorização do homem natural" um modelo de "civilidade" (CANDIDO, 1993, p. 67).

Ora, a arte pastoril, desde o platonismo, aparece "como 'o cuidado voluntariamente oferecido... de rebanhos de seres vivos que o aceitam voluntariamente"" (SLOTERDIJK, 1999, p. 52), com o sentido de domesticar o homem (SLOTERDIJK, 2000, p. 44), o que finalmente se consolida com a democracia moderna, na forma do governo por consentimento legado pelo poder pastoral, que se desloca do cristianismo para toda a sociedade ocidental. $\mathrm{O}$ acontecimento global, portanto, que se antecipa a toda grande civilização e que resulta da cesura entre o humano e o animal no interior do homem, funciona necessariamente mediante uma exclusão e uma inclusão. Conforme o "paradoxo da inclusividade exclusiva" que, segundo Sloterdijk (1999, p. 49), configura a estranheza internalizada de senhor e servo, e se relaciona intimamente com o modelo das sociedades humanistas formadas em torno da literatura e tornadas norma da sociedade em geral. A sociedade finalmente cumpre a proposta das academias, propensas a articular a fícção com a realidade, de modo que o que a literatura, assim como a filosofia, projeta para o ser humano acaba se projetando como uma sombra sobre a realidade. 
A estranheza de senhor e servo, constitutiva do paradoxo da inclusividade exclusiva, encontra sua origem no paradigma do processo descrito por Hegel para oferecer sentido para a realidade, de modo que o triunfo do escravo ocorre com a civilização que, uma vez consumada, permite o se sentir em casa no mundo. Para tanto, a filosofia, que deve estabelecer a necessidade racional do regime estabelecido, conforme a proposição hegeliana segundo a qual o real equivale ao racional, condiz com o movimento final da arte. Segundo Hegel, a grande arte se caracteriza pela "participação na criação continuada do homem pelo homem" (GARAUDY, 1983, p. 180), reiterando, portanto, "a mais antiga das artes, a de repetir o homem pelo homem", conforme Sloterdijk (2000, p. 92). Assim, se o fim dos tempos se consolida, no limite do humanismo hegeliano, com o "homem total", a humanização integral do homem, como concebe Agamben (2006), coincide com uma animalização integral do homem, entrevista, de certa forma, na arte pastoril, progredindo como um processo de alinhamento de todo o mundo.

Mas a domesticação e a amicalização do humanismo livresco obviamente requerem mais que o alfabeto, como observa Sloterdijk (2000, p. 19), ao constatar que o problema do humanismo, que envolve uma definição do ser humano, significa mais que a suposição de que a leitura forma. Ao acentuar o aspecto sombrio do humanismo, Nietzsche (2001, p. 142) identifica a sociabilidade produzida pelo humanismo ao "instinto de rebanho" que caracteriza uma sociedade fraturada, formada por homens cindidos entre homem e animal e os homens mesmos, divididos na nomenclatura nietzscheana entre o animal de rapina e o animal de rebanho. Para Nietzsche (1992a, p. 97), "a necessidade de obedecer" se torna "inata em cada um" na medida em que constitui "a coisa mais longamente exercitada e cultivada entre os homens", de modo que se naturaliza como uma virtude propriamente humana. Ao revelar o "processo de homogeneização dos europeus" que se esconde em termos como "“civilização, 'humanização' ou 'progresso", que caracterizariam a democracia na Europa, Nietzsche (1992a, p. 149-150) explicita a função da "cultura superior" baseada na "espiritualização e no aprofundamento da crueldade" (NIETZSCHE, 1992a, p. 135) para a "resignação" que, conforme Sloterdijk (2000, p. 39), torna o homem "modesto e domesticado". 5

A animalização do homem se consuma, assim, com o consenso da democracia moderna que, caracterizado pela possibilidade de controle pelos meios de comunicação de massa, qualifica um governo por consentimento (AGAMBEN, 2008). O consentimento remete ao motivo pastoral que ilustra a teoria da arte do estadista que, desde Platão, como observa Sloterdijk (1999, p. 52), aparece "como 'o cuidado

\footnotetext{
${ }^{5}$ Nietzsche (1992), ao ironizar que soa ofensivo incluir o homem entre os animais, antecipa o que seria justamente a questão de Heidegger (2005), ao sugerir abandonar o homo animalis em nome de uma humanitas do homo humanus em detrimento da animalitas. Nietzsche (1992a, p. 101), por outro lado, cunha as "expressões 'rebanho', 'instintos de rebanho' e outras semelhantes" para nomear o "instinto do animal de rebanho homem", o qual vincula radicalmente com a moral: "Moral é hoje, na Europa, moral de animal de rebanho". Moral e instinto de rebanho se relacionam de tal forma para Nietzsche (2001, p. 143) que este constata que "quanto mais transparecia no ato o instinto de rebanho (...) tanto mais moral a pessoa se avaliava". Nietzsche (2001, p. 246) conclui que "justamente como bichos domesticados somos um espetáculo vergonhoso e necessitamos do travestimento moral (...) O europeu se disfarça na moral, porque se tornou um animal doente, doentio, estropiado, que tem boas razões para ser 'domesticado', porque é quase um aborto, algo incompleto, fraco, desajeitado...”.
} 
voluntariamente oferecido... de rebanhos de seres vivos que o aceitam voluntariamente"'. E que, antes de informar a filosofia, constitui uma imagem recorrente no Antigo Testamento, frequentemente associada com a imagem da casa como lugar de domesticação. O motivo proveniente do Antigo Testamento culmina, no Novo Testamento, na concepção de Cristo como "porta das ovelhas" e, sobretudo, como "o bom pastor"

A ficção que fundamenta o poder soberano sobre a vida e a morte, o qual, amparado em discursos da civilização e da razão ocidentais, reduz os seres humanos ao estatuto de animais, instaura um estado de exceção que produz uma exclusão de vidas julgadas menos humanas, vidas abandonadas e impossibilitadas de pertencer a uma comunidade humana. Estado de exceção que aparece como estado de direito, para Nietzsche, ou regra geral, para Walter Benjamin, e que se funda no conflito entre a humanidade e a animalidade. Portanto, e por fim, estudar uma literatura cujo conceito implique o homem, "o estudo adequado da humanidade", como quer Pope, requer pensar o homem em detrimento de um humanismo estruturado sobre conceitos como civilidade, universalidade, totalidade ou humanidade, o que nos obriga a voltar a Antonio Candido e questionar o significado de humano em sua definição de literatura.

\section{REFERÊNCIAS}

AGAMBEN, Giorgio. El reino y la gloria: una genealogía de la economía y del gobierno. Buenos Aires: Adriana Hidalgo, 2008.

. Homo sacer: o poder soberano e a vida nua. 2. ed. Belo Horizonte: Ed. UFMG, 2010.

. Lo abierto. Buenos Aires: Adriana Hidalgo, 2006.

ARISTÓTELES. Arte poética. Trad. Eudoro de Souza. Porto Alegre: Globo, 1966.

AUERBACH, Erich. Introdução aos estudos literários. São Paulo: Cosac Naify, 2015.

2009.

Mimesis: a representação da realidade na literatura ocidental. 5. ed. São Paulo: Perspectiva,

BENJAMIN, Walter. Magia e técnica, arte e política: ensaios sobre a literatura e história da cultura. 7. ed. São Paulo: Brasiliense, 1994.

CAMPOS, Haroldo de. O sequestro do barroco na formação da literatura brasileira: o caso Gregório de Mattos. Salvador: Fundação Casa de Jorge Amado, 1989.

CANDIDO, Antonio. Formação da literatura brasileira (momentos decisivos). 7. ed. Belo Horizonte: Itatiaia, 1993.

. Literatura e Sociedade. São Paulo: Companhia Editora Nacional, 1976.

\footnotetext{
${ }^{6}$ A exemplo do Salmo de Davi: “O Senhor é meu pastor, nada me faltará. (...) E habitarei na casa do Senhor por longos dias." (Heb. 23), relacionado com o motivo da casa. Exemplo semelhante se encontra nos cânticos de Salomão: "vai, segue as pisadas das ovelhas, e apascenta os cabritos junto às cabanas dos pastores." (Cântico dos cânticos 1). A noção de controle do rebanho que se insinua aqui se evidencia na voz do Senhor em outros exemplos, como "Ai dos pastores que deixam perder-se e dispersar-se o rebanho miúdo de minha pastagem!" (Jeremias 23) e "por falta de pastor, dispersaram-se minhas ovelhas, e em sua dispersão foram expostas a tornarem-se presa de todas as feras." (Ezequiel 34). O motivo presente nos exemplos, provenientes todos do Antigo Testamento, culmina, no Novo Testamento, na concepção de Cristo como porta das ovelhas, como aparece em João 10: "Jesus tornou a dizer-lhes: 'Em verdade, em verdade vos digo: eu sou a porta das ovelhas.", e sobretudo como o bom pastor: "Eu sou o bom pastor. Conheço as minhas ovelhas e as minhas ovelhas conhecem a mim, como meu Pai me conhece e eu conheço o Pai. Dou a minha vida pelas minhas ovelhas. Tenho ainda outras ovelhas que não são deste aprisco. Preciso conduzi-las também e ouvirão a minha voz e haverá um só rebanho e um só pastor.” (João 10).
} 
COSTA, Lígia Militz da. A poética de Aristóteles: mimese e verossimilhança. São Paulo: Ática, 1992. GARAUDY, Roger. Para conhecer o pensamento de Hegel. Porto Alegre: L\&PM, 1983.

HEIDEGGER, Martin. Carta sobre o humanismo. 2. ed. São Paulo: Centauro, 2005.

NEIMAN, Susan. O mal no pensamento moderno: uma história alternativa da filosofia. Rio de Janeiro: DIFEL, 2003.

NIETZSCHE, Friedrich. A gaia ciência. São Paulo: Companhia das Letras, 2001.

1992a. Além do bem e do mal: prelúdio a uma filosofia do futuro. São Paulo: Companhia das Letras,

. Genealogia da moral: uma polêmica. São Paulo: Companhia das Letras, 1998.

. O nascimento da tragédia ou helenismo e pessimismo. São Paulo: Companhia das Letras, 1992b.

PLATÃO. A república. 9. ed. Trad. Maria Helena da Rocha Pereira. Lisboa: Fundação Calouste Gulbenkian, 2001.

SLOTERDIJK, Peter. No mesmo barco: ensaio sobre a hiperpolítica. São Paulo: Estação Liberdade, 1999.

. Regras para o parque humano: uma resposta à carta de Heidegger sobre o humanismo. São Paulo: Estação Liberdade, 2000.

Recebido em 13/03/2016. Aprovado em 21/08/2016.

Title: Fiction and reality or literature and society: borderlines

Abstract: This paper aims to deepen the meaning of Peter Sloterdijk's statement according to which humanism fails as a school of human development through literature, postulating, therefore, the end of the utopia of human development through literature, which supposedly promotes resignation from reading and writing. To this end, interests the fact of the concept of literature proposed by Sloterdijk as a community subjacent to humanism is consistent with the concept of literature proposed in Brazil by Antonio Candido, considering that Sloterdijk suggests thinking humanism as a society similar to the literary academies mentioned by Candido as Brazilian literature formers, and literature as communicative means to humans form themselves.

Keywords: Literature. Humanism. Society.

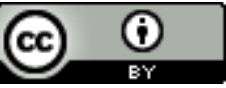

Este texto está licenciado com uma Licença Creative Commons Atribuição 4.0 Internacional. 